\title{
A new brachydactyly syndrome with similarities to Julia Bell types B and E
}

\author{
PAULINE PITT AND IVAN WILLIAMS \\ From the Department of Rheumatology, Kent and Sussex Hospital, Tunbridge Wells, Kent.
}

SUMmARY We report a family with some of the features of both types B and E Julia Bell brachydactyly. We feel therefore that this family may constitute a new syndrome and we would i like to name this after the family involved, the Ballard syndrome.

Brachydactyly, the shortening of digits due to anomalous development of any of the phalanges or metacarpals, was the first inherited disorder recognised in man as showing dominant Mendelian inheritance. ${ }^{1}$ In 1951, Julia Bell classified these abnormalities into five groups. ${ }^{2}$

We report here a family with an unusual type of brachydactyly which shows similarities to Julia Bell types $B$ and $E$. In type $B$, the basic digital malformation pattern involves a symmetrical deformity with absence or hypoplasia of the terminal phalanges in the index to little fingers, with complete or nearly complete absence of the finger nails. The thumbs often show changes in the distal phalanges and digits on the radial side of the hand are less severely affected than on the ulnar side. In type E brachydactyly, there is shortening of one or more of the metacarpals with or without shortening of the metatarsals. ${ }^{3}$

\section{Case reports}

The proband was a 46 year old white male, initially seen in the Rheumatology Department with a torn medial meniscus. During the physical examination it was noted that he had abnormally short ring and little fingers on both hands with marked concavity of the nails on these fingers. In addition to this, his thumbs were broadened and again the nail growth was abnormal, as shown in fig 1 . Otherwise his physical examination was normal. $X$-ray of his hands (fig 2) showed short metacarpals in the ring and little fingers. The terminal phalanges of the thumbs were broader than usual. $X$-ray of his feet (fig 3 ) showed shortened fourth and fifth metatarsals.

The proband's brother and his brother's daughter

Received for publication 27 February 1984

Accepted for publication 6 August 1984 were also examined. The brother's hands (fig 4) and feet (fig 5) showed similar changes to the proband, except that the thumbs were normally proportioned. Figs 6 and 7 show the niece's hands and feet. In all

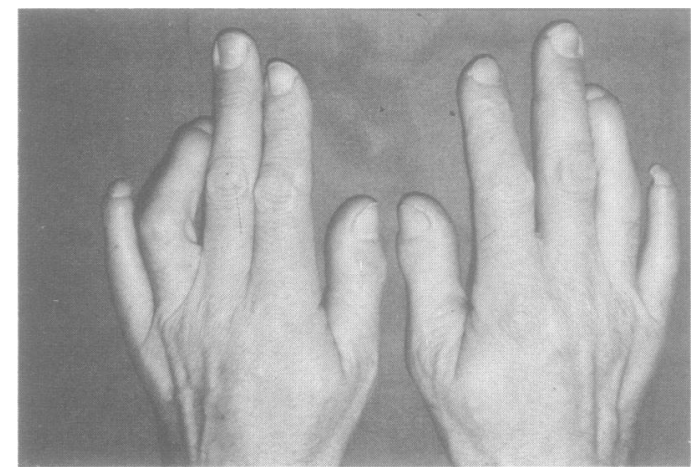

FIG 1 Hands of proband.

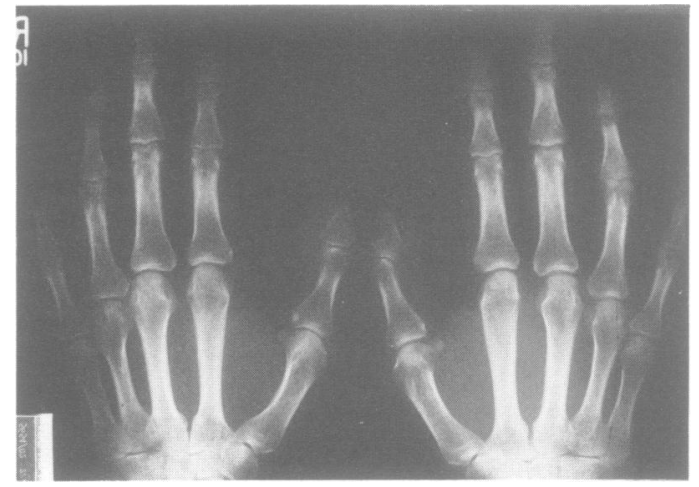

FIG $2 X$-ray of proband's hands. 
three subjects, the growth of the nails on these digits was markedly distorted, and a close-up of the niece's little finger illustrates this well (fig 8).

Afterconsultation with the proband'sgrandmother, it was possible to obtain information on five generations of this pedigree. There were at least 12 affected

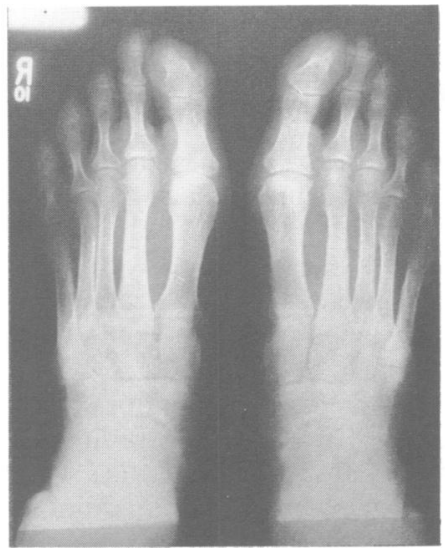

FIG $3 X$-ray of proband's feet.

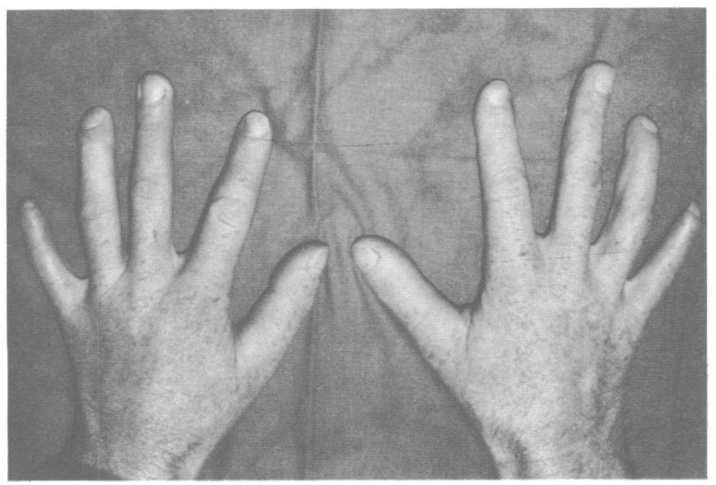

FIG 4 Proband's brother's hands.

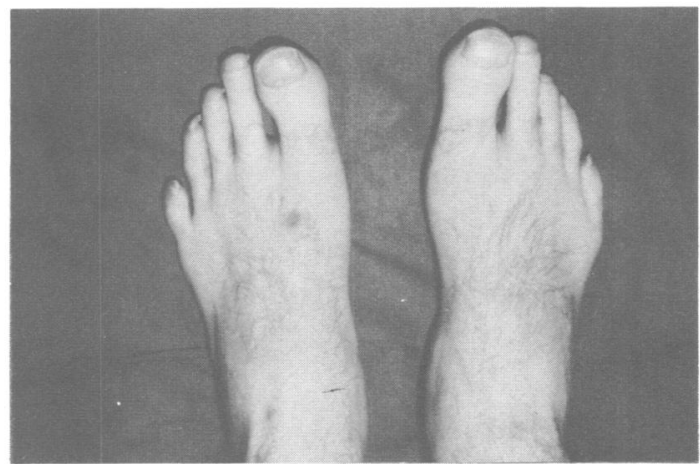

FIG 5 Proband's brother's feet. members, as shown in fig 9. Inheritance appears to be autosomal dominant. No other skeletal abnormalities were noted in any of the affected persons seen, and all were of normal stature or slightly above. There was no history of mental subnormality and the joints were not hyperextensible. The

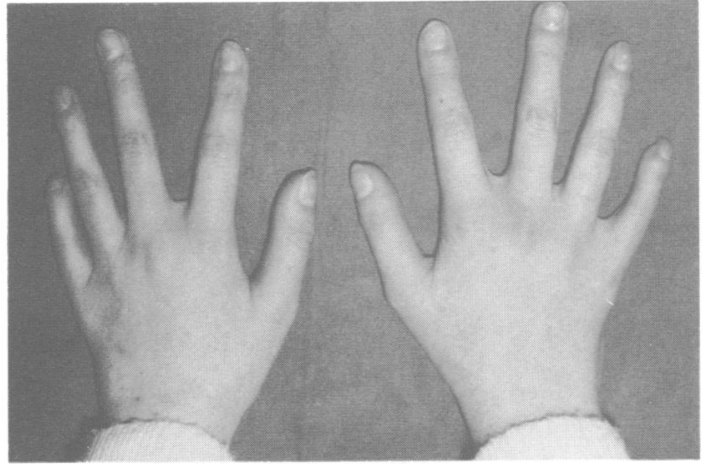

FIG 6 Proband's niece's hands.

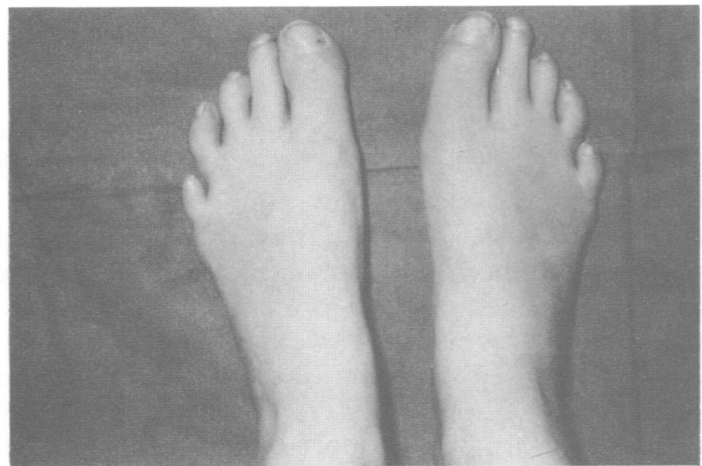

FIG 7 Proband's niece's feet.

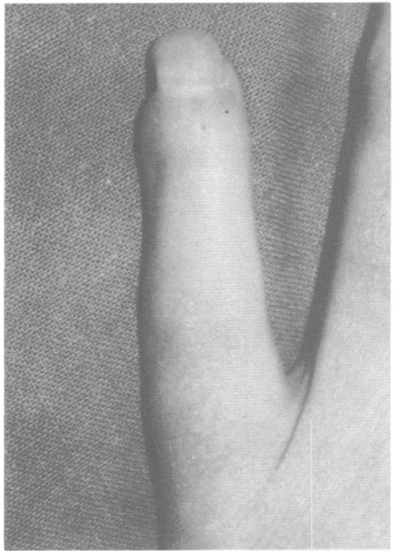

FIG 8 Niece's little finger. 


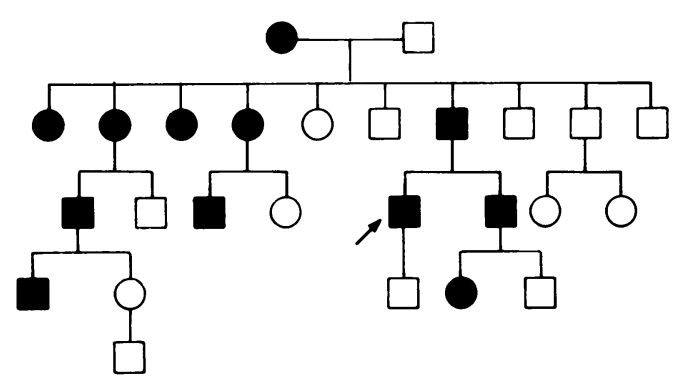

Proband

FIG 9 Family pedigree.

abnormality as documented in the three patients described and that as obtained from the grandmother's history of the other affected members appeared consistent.

HLA typing of the three affected persons and the proband's unaffected son was non-contributory to the inheritance of this disorder.

\section{Discussion}

The apparently consistent abnormality in this pedigree involved shortening of the metacarpals and metatarsals in the fourth and fifth digits of the hands and feet. In association with this, there was marked concavity of the nail growth on these digits, and the distal phalanges of the proband's thumb were broadened. This pedigree, we feel, illustrates some of the features of Julia Bell types B and E brachydactyly. In type $E$ there is variable shortening of the metacarpals with more or less normal length of the phalanges. The inheritance in our family appears to be autosomal dominant and there is no history of subnormality. Our family differs, however, from type $E$ in that the affected subjects were of normal or above normal height. The proband, for example, was over $183 \mathrm{~cm}$ tall and there was no evidence of hyperextensibility of the hands. The families described by Julia Bell with type E demonstrated frequent bilateral asymmetry not present in this pedigree, and she found it was uncommon for the metatarsals to be shortened as well as the metacarpals. In addition to these features, she found that the trait was highly variable in its expressivity, whereas in the family reported here the abnormality appeared to be consistent in the affected persons, apart from the proband who had broad thumbs.

As far as type B brachydactyly is concerned, the family showed some of the features of this group as well, in that the abnormality affected the ulnar side of the hands and feet, the metacarpals and metatar- i sals were shortened in the affected digits, and there $\mathrm{N}$ was some abnormality in nail growth although the 은 nails were still present. The major characteristics of $\rightarrow$ the group, that is, short or rudimentary middle phalanges with absent or short terminal phalanges. were not present, nor were additional features described such as carpal or tarsal fusion, syndactyly, and symphalangism.

\section{References}

${ }^{1}$ Farabee WC. Inheritance of digital malformation in man. Papers, Peabody Museum. Cambridge, Massachussets: Harvard University 3; 1905: 65-78.

${ }^{2}$ Bell J. On brachydactyly and symphalangism. Treasury of human inheritance. Vol 5, part 1. London: Cambridge University Press, 1951.

3 Temtamy SA, McKusick VA. Genetics of hand malformations. New York: Liss, 1978: 203-5.

Correspondence and requests for reprints to $\mathrm{Dr}$ Pauline Pitt, Department of Rheumatology, King's College Hospital, Denmark Hill, London SE59RS. 